\title{
Nurses Readiness Regarding Disaster Preparedness at Alnoor Hospital in Makkah
}

\author{
Afraa N. Kutbi, \\ Post Graduate Student: Nursing College, Medical \& Surgical Nursing \\ Samah Mahmoud Sofar, \\ Assistant professor, medical-surgical nursing department, \\ faculty of nursing, Alexandria University, Egypt \\ Elham Nagshabandi \\ Associated Professor, Medical Surgical Department, \\ faculty of Nursing, King Abdulaziz University, Jeddah-Saudi Arabia
}

\begin{abstract}
Introduction : Disaster occurs every day somewhere in the world with dramatic impact on individuals, families and communities. Nurses are the largest group of health care providers and are considered essential personnel in disaster preparedness. Aim: To assess the level of nurses' readiness regarding disaster preparedness at alnoor hospital in Makkah Method: a quantitative cross sectional descriptive design. Setting: the study conducted at Alnoor Hospital in, medical, surgical, emergency and critical care unit Departments. Subjects: a convenient sample of 194 nurses was selected to participate in the study. Tool: the study included one tool which divided into two parts, Part I. demographic and work related data, and part II. Nurses' readiness regarding hospital disaster preparedness questionnaire. Result: Nearly half of the nurses (49\%) had moderate level of readiness regarding disaster preparedness. There was no significant relation between nurses' readiness with age, gender, educational level of nurses, years of experience and attend of previous drill workshop (p. 0.196, 0.418, 0.805, 0.133, 0.216) respectively. While there was a significant relationship between nurses' readiness for disaster preparedness with the specialty practice area of nurses, current professional role, and actively participated in an actual major disaster event (p. 0.000, 0.004, 0.001) respectively. Conclusion: concerning total readiness nearly half of the nurses had moderate level of readiness regarding disaster preparedness'. Moreover, more than half of nurses had moderate level of readiness regarding emergency preparedness terms and activities, communication and connectivity, assessing critical and nurse's assessment readiness. While less than half of nurses had moderate level of readiness regarding ethical issues in triage, epidemiology and surveillance, decontamination and psychological issue. Recommendations: Further education and training courses are needed to enhance nurses' readiness for disaster preparedness.
\end{abstract}

Keywords: disaster, readiness, preparedness, Nurses

DOI: $10.7176 / \mathrm{JHMN} / 71-07$

Publication date: February $29^{\text {th }} 2020$

\subsection{Introduction}

Disaster occurs every day somewhere in the world with dramatic impact on individuals, families and communities. Most of disasters are uncontrollable and inevitable (Magnaye, Lindsay, Muñoz, Muñoz, and Muro, 2011). In Saudi Arabia, there are about $60 \%$ increasing in disasters in the last decade (Alamri, 2010). A biological example of the July 1990 The Hajj disaster Makkah, Saudi Arabia Crush caused by lack of directional flow of pilgrims and crowd control in the tunnel lead to 1426 deaths, and no data is available for injured (Alamri, 2010; Abosuliman, Kumar, and Alam, 2013).

While in 2009, Jeddah floods cues 163 death and 11640 injuries, repeated Jeddah floods 2011 cues 10 deaths and 5000 injuries (Alharbi, 2014). Prior to Hajj 2015 the crane falls due to its wrong positioning which has killed more than 107 Muslims along with injuring 232. Followed by Hajj 2015 incidence of crowded when more than 2700 death and unknown number of injured patient (Abosuliman, Kumar, and Alam, 2013).

Japan, China, Indonesia are the countries which faced at least one natural disaster per year. In 2016, 342 disasters triggered by natural hazards were registered. The number of deaths caused by natural disasters was 8,733 (Guha-Sapir, Hoyois, and Below, 2017). Disasters have an impact on human life, so it requires prevention and collaboration efforts to minimize or prevent greater damages from it (Magnaye, Lindsay, Muñoz, Muñoz, and Muro, 2011). A disaster is defined as severe destruction of the systems that render a community or society functional, leading to great losses of human life. Readiness is a state of being ready or prepared for disaster action preparedness is a state of being prepared or ready always, nurses readiness requiring disaster preparedness through continuing training and drills (Pourvakhshoori, et al., 2014) .

Disasters can be categorized as external disaster and internal disaster, internal disaster means inside the 
hospital, external disaster occur outside the hospital. Other classifications of disasters either man-made or natural disaster, man-made such as terrorist, natural disaster such as floods and twister (Turale, 2014). Man-made disasters have been witnessed in Saudi Arabia such as terrorist attacks happened in many countries such as Riyadh and Khobar (Ibrahim, 2014).

Disaster nurses readiness is essential to provide adequate health care and addressing the humanitarian challenges of disasters (Diab, and Mabrouk, 2015). Nurses are the largest manpower among health care providers working in any health care sector and are considered essential personal in disaster (Lowe, and F.I. Hummel, 2014). Moreover, nurses represent an indispensable work force during disaster. The fundamental attributes of the nursing practice are to provide care to injured or ill patient, assist individual and families to deal with physical and emotional issues and work to improve health and wellbeing with in the community (Achora, and Kamanyire, 2016).

Nurses collaborate with other experts, including environmentalists, epidemiologists, laboratory workers, biostatisticians, physicians, social workers and many others. Nurses have been a part of disaster preparedness; so Nurses should be assessed for readiness to measure her abilities to work in a disaster and to meet the needs of the respective serving country (Diab, and Mabrouk, 2015). However, some of nurses might not feel ready to provide care for patients during disasters situations despite continuous training and drills through Scenarios (Evans, and Baumberger-Henry, 2015). Local and international initiatives are in place to adequately prepare nurses and other healthcare workers to respond effectively to disasters through extensive disaster training, disaster drills and exercises, and the provision of disaster management courses with the expectation that nurses should be able to deliver adequate nursing care to the communities affected by disasters (Corrigan, and Samrasinghe, 2012). In spite of these initiatives, available evidence has shown that nurses remain inadequately prepared to respond to disasters and are uncertain of their roles during these events (Usher, et al. 2015).

\subsection{Significant of the study:}

During working in hospitals, it has been observed that nurses rarely knew about the disaster preparedness plans in their hospital and not aware of the procedures that exist for dealing with disasters. This study contributes to assess nurse's readiness regarding hospital disaster preparedness. Therefore, it is essential that qualified nurses should be ready to respond and participate in disasters preparedness. Continuous developing specialized education and training is very important to beat this problem. It was recommended by the World Health Organization (WHO) that all nations, no matter how frequent or infrequent the happenings, healthcare workers should be prepared healthcare workers for a disaster. Exploring and understanding nurse's readiness for disaster preparedness and their role during disaster will provide sound and valuable information, providing a direction in the areas of health care education and research development for disaster preparedness in Makkah Region.

\subsection{Operational definition:}

Disaster preparedness is the fundamental attributes of the nursing practice to provide care to injured or ill patient, assist individual and families to deal with physical and emotional issues and work to improve health and wellbeing within the community.

\subsection{Aim of the study:}

To assess the level of nurses' readiness regarding disaster preparedness at alnoor hospital in Makkah

\subsection{Questions of the research:} Makkah?

1-What is the level of nurses' readiness regarding disaster preparedness at Alnoor general hospital in

2-What is the relation between the level of nurse's readiness with demographic and work related characteristic of nurses?

\subsection{RESEARCH METHODOLOGY}

\subsection{Research design:}

Quantitative, cross sectional descriptive design was used in this study.

\subsection{Research setting:}

The study has been conducted at medical, surgical, emergency and critical care unit Departments of Alnoor Hospital in Holly City of Makkah which is the largest emergency department in all medical surgical and education training program center. Makkah is the Holy City in Kingdom of Saudi Arabia and has approximately $25.7 \%$ of Saudi population, according to the estimation of central department of statistic and information, in Ministry of Health (2016). The society comes from different ethics, culture backgrounds because the city serves pilgrims. Alnoor Hospital is located in the main street in Makkah. It provides care for clients from three main holy places Mina, Arafat, and Muzdalifa. It receives 420 clients every day; the hospital units had three shifts per day. 


\subsection{Study sample:}

Burns, \& Grove, (2016) defined sampling as process where a group of clients select a behavior or an event by ethic to conduct a study. Convenience sample was selected from Alnoor Hospital. A total number of nurses was (400). The estimated population size is based on the latest statistics from nurses (lofficel, 2017). Raosoft software was used for sample size calculated in unit, with the margin of error $5 \%$, confidence level $95 \%$, and estimated response rate $90 \%$ so the required sample size was calculated to be 194 nurses

\subsection{Tool of the study:}

In order to fulfill the aim of the study, one tool had been used by the researcher for the data collection, it includes two parts.

\section{Part I: demographic and work related data:}

This part developed by the researcher. It aimed to assess nurses' demographics and work related data. Demographic data included age, gender and educational level. work related data included current position, year of experience, and attending special training relevant to topic

\section{Part II: Nurses Readiness Regarding Hospital Disaster Preparedness questionnaire:}

This part developed by Wisniewski, Dennik- Champion, \& Peltier, (2004). It aimed to assess nurse's readiness regarding hospital disaster preparedness. It included 34 questions that cover nine dimensions related to emergency readiness as following: Emergency preparedness ( 7 items), Triage (4 items), Epidemiology and surveillance (4 items), Documentation (3 items), Communication connectivity ( 7 items), Psychological issue (4 items), Special population (2 items), Accessing critical (3 items), Assessment and readiness (2 items). Likert scale response was used in which 3 (From 2.34 to 3.00) indicate high level of readiness, 2 (From 1.67 to 2.33) indicate moderate level of readiness, while 1 (From 1 to 1.66) indicate low level of readiness. Study participant select the answer that reflect their readiness to activity.

\subsection{Validity:}

The content of tool was revised by 5 experts in field of medical surgical department faculty of nursing at King Abdul Aziz University to test content validity, completeness, and clarity of items. The comments, a suggestion of jury considered and the tool modified accordingly.

\subsection{Reliability:}

In this study, the reliability of the tool was examined by using Cronbach's alpha, which is an indicator of internal consistency of the scale. The Cronbach's alpha value for the tool was (0.971).

\subsection{Pilot study:}

A pilot study was conducted on $10 \%$ of the study participants (23 nurses) to assess nurses' readiness regarding disaster preparedness. Pilot study was done to test clarity, visibility and applicability of the study tool. The necessary modification was done accordingly. Participants in the pilot study were excluded from the original study.

\subsection{Data collection procedure:}

After securing the administrative approval, written informed consent for participant was obtained after explanation of the aim of the study. Confidentiality and privacy assured for all participants.

- $\quad$ The investigator collected data from five to ten nurses during each morning shift in the break time to avoid disturb the work hours

- After explaining the aim of the study, the investigator distributed the questionnaire to each nurse to complete fill it.

- After half an hour, the investigator collected the questionnaire from each nurse.

- The researcher had to code the questionnaire to be easy entry in to computer and data to analyze during statistical package for social science (SPSS, for window. Version 22).

\subsection{Ethical considerations:}

The researcher assured that the conduction of the study is not affect the work in study setting. The researcher participated following ethical approval and the appropriate license from hospital in order to conduct study. An official letter from the Faculty of Medical- Surgical Nursing Department of post graduate studies in King AbdulAziz University sent to authorities of Alnoor Hospital in Makkah to take approval to collect the data, permission to carry out the study have been obtained from the administration of the chosen setting after explaining the reason for the study. The digital data is not included name or identifying personal data. Furthermore, information received from the nurses treated confidentially and privacy assured for all participants, each nurse allocated a code to ensure anonymity of collected data. Keep secure till the study completed once the study is published. 


\subsection{Data Analysis:}

Data were analyzed using the Statistical Package for Social Sciences (SPSS) version 22 for Windows. Descriptive statistics was conducted to describe variables in frequency, percentage, means and stander deviations. Analysis of variance Chi-square test was performed to examine the relation between nurse's readiness scores with demographic and work related characteristic.

\subsection{RESULT}

\section{1 demographic and work related Characteristics}

Table (1) presents the frequency distribution of demographic and work related characteristics of nurses. Nearly half of the nurses' $(48.9 \%$ ) their age ranged between $20<30$ years old, while only $1.55 \%$ ranged from $50 \leq 60$ years old. The majority $(93.8 \%)$ of nurses were female. Regarding education, the majority $(82.4 \%)$ were had bachelor degree in nursing. Nearly one third of nurses $(39.6 \%)$ had $2<5$ years of experience. Out of the total study's participants, $13.4 \%$ were working in the surgical units, $19 \%$ in medical units, $25.7 \%$ in critical care units and $41.7 \%$ in emergency units. The majority $(90.7 \%)$ of the nurses were register nurse and only $3.6 \%$ were advance practice registered nurses. More than two third of nurses (70.6\%) attended drill/work shop related to disaster management, however, more than half (56.7\%) had never actively participated in an actual major disaster event. Nearly three quarters $(74.7 \%)$ of nurses had never worked in a post-disaster shelter.

Table 1: Frequency Distribution of demographic and work related Characteristics of Nurses.

\begin{tabular}{|c|c|c|}
\hline demographic and work related Characteristics of Nurses. & $\mathrm{N}=194$ & $\%$ \\
\hline \multicolumn{3}{|l|}{ Age } \\
\hline $20<30$ years & 95 & 48.97 \\
\hline $30<40$ years & 71 & 36.60 \\
\hline $40<50$ years & 25 & 12.89 \\
\hline $50 \leq 60$ years & 3 & 1.55 \\
\hline \multicolumn{3}{|l|}{ Gender } \\
\hline Male & 12 & 6.19 \\
\hline Female & 182 & 93.81 \\
\hline \multicolumn{3}{|l|}{ Education } \\
\hline Diploma & 31 & 15.98 \\
\hline Bachelor & 160 & 82.47 \\
\hline Master & 3 & 1.55 \\
\hline \multicolumn{3}{|l|}{ Experiences } \\
\hline 6 months $<2$ years & 23 & 11.86 \\
\hline $2<5$ years & 77 & 39.69 \\
\hline $5<10$ years & 57 & 29.38 \\
\hline $10 \leq 20$ years & 33 & 17.01 \\
\hline More than 20years & 4 & 2.06 \\
\hline \multicolumn{3}{|l|}{ A drill /work shop } \\
\hline Yes & 137 & 70.62 \\
\hline No & 57 & 29.38 \\
\hline \multicolumn{3}{|l|}{ Specialty practice area } \\
\hline Medical unit & 37 & 19.07 \\
\hline Surgical unit & 26 & 13.40 \\
\hline Critical Care unit & 50 & 25.77 \\
\hline Emergency unit & 81 & 41.75 \\
\hline \multicolumn{3}{|l|}{ Professional role } \\
\hline Assistant nurse & 11 & 5.67 \\
\hline Register nurse & 176 & 90.72 \\
\hline Advanced Practice RN & 7 & 3.61 \\
\hline \multicolumn{3}{|c|}{ Have you ever actively participated in an actual major disaster event? } \\
\hline Yes & 84 & 43.30 \\
\hline No & 110 & 56.70 \\
\hline \multicolumn{3}{|l|}{ Have you ever worked in a post-disaster shelter? } \\
\hline Yes & 49 & 25.26 \\
\hline No & 145 & 74.74 \\
\hline
\end{tabular}




\subsection{Nurses Readiness regarding Disaster Preparedness}

Table (2): shows frequency distribution of nurses' readiness regarding to disaster preparedness terms and activities. It was observed that more than two third (69\%) of nurses had moderate level of readiness, while only $16 \%$ of nurses had low level of readiness related to sign and symptoms of exposure to different biological agents. For sign and symptoms of anthrax inhalation, it was found that more than one half $54.6 \%$ of the nurses had moderate level of readiness and $22.7 \%$ had low level of readiness. Moreover, nearly two thirds $(62.9 \%)$ of the nurses had moderate level of readiness and $(11.9 \%)$ had low readiness related to mode of transmission of different types of biological agents. Likewise, more than half $(56.2 \%)$ of nurses had moderate level of readiness while (17.7 \%) nurses had low level of readiness regarding the matching of antidote and prophylactic medications to specific biological/chemical agents. Similarly, more than half $(57.7 \%)$ of nurses had moderate level of readiness while $18 \%$ nurses had low level of readiness for knowing possible adverse reactions to smallpox vaccination. In term of basic first aid in a large-scale emergency event including oxygen administration and ventilation, more than half (54.6\%) of nurses had moderate level of readiness while $8.8 \%$ nurses had low level of readiness. Similarly, more than half $(53.6 \%)$ of nurses had moderate level of readiness and $13.9 \%$ nurses had low level of readiness regarding the evaluation of their own actions during a large-scale emergency event.

Table (2): Frequency distribution of nurses' readiness regarding emergency preparedness terms and activities $(n=194)$

\begin{tabular}{|c|c|c|c|c|c|c|}
\hline \multirow[t]{2}{*}{ Items } & \multicolumn{2}{|c|}{$\begin{array}{l}\text { Low } \\
(1)\end{array}$} & \multicolumn{2}{|c|}{$\begin{array}{l}\text { Moderate } \\
\text { (2) }\end{array}$} & \multicolumn{2}{|c|}{$\begin{array}{l}\text { High } \\
\text { (3) }\end{array}$} \\
\hline & $\mathbf{N}$ & $\%$ & $\mathbf{N}$ & $\%$ & $\mathbf{N}$ & $\%$ \\
\hline $\begin{array}{l}\text { Signs/symptoms of exposure to different biological } \\
\text { agents }\end{array}$ & 31 & $16.0 \%$ & 134 & $69.1 \%$ & 29 & $14.9 \%$ \\
\hline Signs/symptoms of anthrax inhalation & 44 & $22.7 \%$ & 106 & $54.6 \%$ & 44 & $22.7 \%$ \\
\hline $\begin{array}{l}\text { Modes of transmission for different types of } \\
\text { biological agents (i.e. anthrax, smallpox) }\end{array}$ & 23 & $11.9 \%$ & 122 & $62.9 \%$ & 49 & $25.3 \%$ \\
\hline $\begin{array}{l}\text { Match antidote and prophylactic medications to } \\
\text { specific biological/chemical agents }\end{array}$ & 34 & $17.5 \%$ & 109 & $56.2 \%$ & 51 & $26.3 \%$ \\
\hline Possible adverse reactions to smallpox vaccination & 35 & $18.0 \%$ & 112 & $57.7 \%$ & 47 & $24.2 \%$ \\
\hline $\begin{array}{l}\text { Basic first aid in a large-scale emergency event } \\
\text { (including oxygen administration and ventilation) }\end{array}$ & 17 & $8.8 \%$ & 106 & $54.6 \%$ & 71 & $36.6 \%$ \\
\hline $\begin{array}{l}\text { How to evaluate the effectiveness of your own } \\
\text { actions during a large-scale emergency event }\end{array}$ & 27 & $13.9 \%$ & 104 & $53.6 \%$ & 63 & $32.5 \%$ \\
\hline
\end{tabular}

Table (3): illustrates the frequency distribution of nurses' readiness regarding ethical issues in triage. It was noticed that nearly two third $(63.3 \%)$ of the nurses had moderate level of readiness related to performance of rapid physical assessment of victim of a large-scale emergency event. Similarly, nearly two third of the nurses $(62.4 \%)$ had moderate level of readiness and $14.4 \%$ had low level of readiness regarding performance of rapid mental health assessment of a victim of a large-scale emergency event. In terms of how to assist with triage in a largescale emergency event, around half of the nurses (50.5\%) had moderate level of readiness while only $10.8 \%$ of the nurses had low level of readiness. Additionally, more than half $(53.1 \%)$ of the nurses had moderate level of readiness whereas, $12.9 \%$ of the nurses had low level of readiness of general issues related to the proper handling of the dead during a large-scale emergency event such as ethical, legal, cultural, and safety.

Table (3): Frequency distribution of nurses' readiness regarding preparedness with ethical issues in triage $(\mathbf{n}=194)$

\begin{tabular}{|l|l|l|l|l|l|l|}
\hline \multirow{2}{*}{ Items } & \multicolumn{2}{l|}{$\begin{array}{l}\text { Low } \\
\text { (1) }\end{array}$} & \multicolumn{2}{l|}{$\begin{array}{l}\text { Moderate } \\
\text { (2) }\end{array}$} & \multicolumn{2}{l|}{$\begin{array}{l}\text { High } \\
\text { (3) }\end{array}$} \\
\cline { 2 - 6 } $\begin{array}{l}\text { How to perform a rapid physical assessment of } \\
\text { victim of a large-scale emergency event }\end{array}$ & 17 & $8.8 \%$ & 124 & $63.9 \%$ & 53 & $27.3 \%$ \\
\hline $\begin{array}{l}\text { How to perform a rapid mental health assessment } \\
\text { of a victim of a large-scale emergency event }\end{array}$ & 28 & $14.4 \%$ & 121 & $62.4 \%$ & 45 & $23.2 \%$ \\
\hline $\begin{array}{l}\text { How to assist with triage in a large-scale } \\
\text { emergency event }\end{array}$ & 21 & $10.8 \%$ & 98 & $50.5 \%$ & 75 & $38.7 \%$ \\
\hline $\begin{array}{l}\text { General issues related to the proper handling of } \\
\text { the dead during a large-scale emergency event } \\
\text { (ethical, legal, cultural, and safety) }\end{array}$ & 25 & $12.9 \%$ & 103 & $53.1 \%$ & 66 & $34.0 \%$ \\
\hline
\end{tabular}

Table (4): reveals the frequency distribution of nurses' level of readiness regarding epidemiology and surveillance. More than half of the nurses (59.8\%) had moderate level of readiness while only $10.8 \%$ of the nurses had low level of readiness regarding appropriate personal protective equipment when caring for patient exposed 
to a biological, chemical, or radiological agent. Concerning time to report an unusual set of symptoms to an epidemiologist, more than half (56.2\%) of the nurses had moderate level of readiness, and only $14.9 \%$ of the nurses had low level of readiness. Similarly, more than half $(54.6 \%)$ of the nurses had moderate level of readiness and only $15.5 \%$ of the nurses had low level of readiness related to diseases that are immediately reported to state health departments. Regarding the ability to identify the exacerbation of an underlying disease due to exposure to a chemical or biological agent, or to radiation, more than half of the nurses $(57.7 \%)$ had moderate level of readiness while $13.4 \%$ nurses had low level of readiness.

Table (4): Frequency distribution of nurse's readiness regarding epidemiology and surveillance $(n=194)$

\begin{tabular}{|c|c|c|c|c|c|c|}
\hline \multirow[t]{2}{*}{ Items } & \multicolumn{2}{|c|}{$\begin{array}{l}\text { Low } \\
(1)\end{array}$} & \multicolumn{2}{|c|}{$\begin{array}{l}\text { Moderate } \\
\text { (2) }\end{array}$} & \multicolumn{2}{|c|}{$\begin{array}{l}\text { High } \\
\text { (3) }\end{array}$} \\
\hline & $\mathbf{N}$ & $\%$ & $\mathbf{N}$ & $\%$ & $\mathbf{N}$ & $\%$ \\
\hline $\begin{array}{l}\text { History of the appropriate personal protective } \\
\text { equipment when caring for patient exposed to a } \\
\text { biological, chemical, or radiological agent }\end{array}$ & 21 & $10.8 \%$ & 116 & $59.8 \%$ & 57 & $29.4 \%$ \\
\hline $\begin{array}{l}\text { Time to report an unusual set of symptoms to an } \\
\text { epidemiologist }\end{array}$ & 29 & $14.9 \%$ & 109 & $56.2 \%$ & 56 & $28.9 \%$ \\
\hline $\begin{array}{l}\text { Diseases that are immediately reported to state } \\
\text { health departments }\end{array}$ & 30 & $15.5 \%$ & 106 & $54.6 \%$ & 58 & $29.9 \%$ \\
\hline $\begin{array}{l}\text { Ability to identify the exacerbation of an } \\
\text { underlying disease due to exposure to a chemical } \\
\text { or biological agent, or to radiation }\end{array}$ & 26 & $13.4 \%$ & 112 & $57.7 \%$ & 56 & $28.9 \%$ \\
\hline
\end{tabular}

Table (5): depicts the frequency distribution of nurses' readiness regarding decontamination. It showed that more than half of the nurses $(52.1 \%)$ had moderate level of readiness whereas only $8.8 \%$ of nurses had low level of readiness in respect of selection of the appropriate personal protective equipment (PPE) when caring for patients exposed to a biological, chemical or radiological agent. Likewise, regarding the decontamination procedures stated in your facility's emergency operations plan, more than half $(53.1 \%)$ of the nurses had moderate level of readiness whereas, nearly $13.9 \%$ of the nurses had low level of readiness. Furthermore, more than half $(54.1 \%)$ of the nurses had moderate level of readiness and about $14.9 \%$ of the nurses had low level of readiness in terms of the impact on environment from a large-scale emergency event.

Table (5): Frequency distribution of readiness regarding decontamination $(n=194)$

\begin{tabular}{|l|l|l|l|l|l|l|}
\hline \multirow{2}{*}{ Items } & \multicolumn{2}{l|}{$\begin{array}{l}\text { Low } \\
(\mathbf{1})\end{array}$} & $\mathbf{N}$ & \multicolumn{2}{l|}{$\begin{array}{l}\text { Moderate } \\
\text { (2) }\end{array}$} & \multicolumn{2}{l|}{$\begin{array}{l}\text { High } \\
\text { (3) }\end{array}$} \\
\cline { 2 - 7 } & $\mathbf{N}$ & $\mathbf{\%}$ & $\mathbf{N}$ & $\%$ \\
\hline $\begin{array}{l}\text { Selection of the appropriate personal protective } \\
\text { equipment (PPE) when caring for patients exposed } \\
\text { to a biological, chemical or radiological agent }\end{array}$ & 17 & $8.8 \%$ & 101 & $52.1 \%$ & 76 & $39.2 \%$ \\
\hline $\begin{array}{l}\text { The decontamination procedures stated in your } \\
\text { facility's Emergency Operations Plan }\end{array}$ & 27 & $13.9 \%$ & 103 & $53.1 \%$ & 64 & $33.0 \%$ \\
\hline $\begin{array}{l}\text { The impact on environment from a large-scale } \\
\text { emergency event }\end{array}$ & 29 & $14.9 \%$ & 105 & $54.1 \%$ & 60 & $30.9 \%$ \\
\hline
\end{tabular}

Table (6): reveals the frequency distribution of nurses' readiness regarding communication and connectivity. It illustrated that nearly two third (64.4\%) of nurses had moderate level of readiness whereas $13.9 \%$ of the nurses had low level of readiness in respect to the procedure used to document provision of care in a large-scale emergency event. Although only few (14.4\%) of the nurses had low level of readiness regarding chain of custody during a large-scale emergency event, but more than a half $(58.8 \%)$ of the nurses had moderate level of readiness and less than one third (26.8\%) had high level of readiness related to it. Additionally, regarding the procedures for communicating critical patient information to those transporting patients, more than a half $(58.8 \%)$ had moderate level of readiness and only $9.3 \%$ of the nurses had low level of readiness. Nearly two third (63.9\%) of the nurses had moderate level of readiness and only $22.2 \%$ of nurses had high level of readiness regarding how effectively presents information about degree of risk to various audiences. Moreover, related to how to identify the different abilities of key partners in your Emergency Operations Plan (EOP), more than half (60.3\%) of the nurses had moderate level of readiness while only $16.5 \%$ nurses have low level of readiness. Similarly, more than a half $(59.3 \%)$ of the nurses had moderate readiness while less than one-third $(27.8 \%)$ nurses had high level of readiness in regards of appropriate debriefing activities following a large-scale emergency event. In respect of how to use of all types of communication devices as phone, fax, email, satellite phones, PDAs) more than a half (59.3\%) of the nurses had moderate level of readiness and less than one-third $27.3 \%$ of the nurses had high level of readiness. 
Table (6): Frequency distribution of nurses' readiness regarding communication/ connectivity $(\mathrm{n}=194)$

\begin{tabular}{|c|c|c|c|c|c|c|}
\hline \multirow{2}{*}{ Items } & \multicolumn{2}{|c|}{$\begin{array}{l}\text { Low } \\
\text { (1) }\end{array}$} & \multicolumn{2}{|c|}{$\begin{array}{l}\text { Moderate } \\
\text { ( 2) }\end{array}$} & \multicolumn{2}{|c|}{$\begin{array}{l}\text { High } \\
\text { (3) }\end{array}$} \\
\hline & $\mathbf{N}$ & $\%$ & $\mathbf{N}$ & $\%$ & $\mathbf{N}$ & $\%$ \\
\hline $\begin{array}{l}\text { The procedure used to document provision of care } \\
\text { in a large-scale emergency event }\end{array}$ & 27 & $13.9 \%$ & 125 & $64.4 \%$ & 42 & $21.6 \%$ \\
\hline $\begin{array}{l}\text { Effectively present information about degree of } \\
\text { risk to various audiences }\end{array}$ & 27 & $13.9 \%$ & 124 & $63.9 \%$ & 43 & $22.2 \%$ \\
\hline $\begin{array}{l}\text { Identify the different abilities of key partners in } \\
\text { your Emergency Operations Plan (EOP) }\end{array}$ & 32 & $16.5 \%$ & 117 & $60.3 \%$ & 45 & $23.2 \%$ \\
\hline $\begin{array}{l}\text { Appropriate debriefing activities following a large- } \\
\text { scale emergency event }\end{array}$ & 25 & $12.9 \%$ & 115 & $59.3 \%$ & 54 & $27.8 \%$ \\
\hline $\begin{array}{l}\text { Use of all types of communication devices (phone, } \\
\text { fax, email, satellite phones, PDAs) }\end{array}$ & 26 & $13.4 \%$ & 115 & $59.3 \%$ & 53 & $27.3 \%$ \\
\hline $\begin{array}{l}\text { Chain of custody during a large-scale emergency } \\
\text { event }\end{array}$ & 28 & $14.4 \%$ & 114 & $58.8 \%$ & 52 & $26.8 \%$ \\
\hline $\begin{array}{l}\text { Procedures for communicating critical patient } \\
\text { information to those transporting patients }\end{array}$ & 18 & $9.3 \%$ & 114 & $58.8 \%$ & 62 & $32.0 \%$ \\
\hline
\end{tabular}

Table (7) shows frequency distribution of nurses' readiness regarding psychological issues. Nearly two third $(61.3 \%)$ of the nurses had moderate level of readiness while $16 \%$ of the nurses had low readiness in provision of appropriate psychological support for all parties involved in a large-scale emergency event. In regards of provide health counseling and education to patient regarding the long-term impact of chemical, biological, radiological, nuclear and explosive (CBRNE) agents, more than half $(59.8 \%)$ of the nurses had moderate level of readiness and $14.4 \%$ had low level of readiness. Similarly, related to signs of post-traumatic stress in patients seen for routine health care following an event, more than a half (56.2\%) had moderate level of readiness and less than one-third $(28.9 \%)$ had high level of readiness. Additionally, more than half $(53.6 \%)$ of the nurses had moderate level of readiness while about one-third $(29.5 \%)$ of the nurses had high level of readiness regarding the evaluation of a teenager to detect post-traumatic mental health problems.

Table (7): Frequency distribution of nurses' readiness regarding Psychological issues (n=194)

\begin{tabular}{|l|l|l|l|l|l|l|}
\hline \multirow{2}{*}{ Items } & \multicolumn{2}{l|}{$\begin{array}{l}\text { Low } \\
\text { (1) }\end{array}$} & $\mathbf{N}$ & \multicolumn{2}{l|}{$\begin{array}{l}\text { Moderate } \\
\text { (2) }\end{array}$} & \multicolumn{2}{l|}{$\begin{array}{l}\text { High } \\
\mathbf{( 3 )}\end{array}$} \\
\cline { 2 - 6 } & $\mathbf{N}$ & $\mathbf{\%}$ & $\mathbf{\%}$ \\
\hline $\begin{array}{l}\text { Appropriate psychological support for all parties } \\
\text { involved in a large-scale emergency event }\end{array}$ & 31 & $16.0 \%$ & 119 & $61.3 \%$ & 44 & $22.7 \%$ \\
\hline $\begin{array}{l}\text { Provide health counseling/education to patient } \\
\text { regarding the long-term impact of chemical, } \\
\text { biological, radiological, nuclear and explosive } \\
\text { (CBRNE) agents }\end{array}$ & 28 & $14.4 \%$ & 116 & $59.8 \%$ & 50 & $25.8 \%$ \\
\hline $\begin{array}{l}\text { Signs of post-traumatic stress in patients seen for } \\
\text { routine health care following an event }\end{array}$ & 29 & $14.9 \%$ & 109 & $56.2 \%$ & 56 & $28.9 \%$ \\
\hline $\begin{array}{l}\text { How to evaluate a teenager to detect post- } \\
\text { traumatic mental health problems }\end{array}$ & 33 & $17.0 \%$ & 104 & $53.6 \%$ & 57 & $29.4 \%$ \\
\hline
\end{tabular}

Table (8) depicts frequency distribution of nurses' readiness regarding special populations. It is shown that more than half $(58.2 \%)$ of the nurses had moderate level of readiness, and $15.5 \%$ had low readiness level related to procedures for providing care to children or youth during a large-scale emergency event in cases where prior consent from parent or legal guardian is not possible. However, majority $(88.1 \%)$ of the nurses had moderate level of readiness related to the appropriate care of sensitive and vulnerable patient groups during a large-scale emergency as aged, pregnant women and the disabled, and only $9.3 \%$ of the nurses had high level of readiness related to it. 
Table (8): Frequency distribution of nurses' readiness regarding special populations $(\mathrm{n}=194)$

\begin{tabular}{|c|c|c|c|c|c|c|}
\hline \multirow[t]{2}{*}{ Items } & \multicolumn{2}{|c|}{$\begin{array}{r}\text { Low } \\
\text { ( } 1 \text { ) }\end{array}$} & \multicolumn{2}{|c|}{$\begin{array}{l}\text { Moderate } \\
\text { ( 2 ) }\end{array}$} & \multicolumn{2}{|c|}{$\begin{array}{l}\text { High } \\
\text { (3) }\end{array}$} \\
\hline & $\mathbf{N}$ & $\%$ & $\mathbf{N}$ & $\%$ & $\mathbf{N}$ & $\%$ \\
\hline $\begin{array}{l}\text { Procedures for providing care to children/youth } \\
\text { during a large-scale emergency vent in cases where } \\
\text { prior consent from parent/legal guardian is not } \\
\text { possible }\end{array}$ & 30 & $15.5 \%$ & 113 & $58.2 \%$ & 51 & $26.3 \%$ \\
\hline $\begin{array}{l}\text { The appropriate care of sensitive /vulnerable patient } \\
\text { groups during a large-scale emergency (aged, } \\
\text { pregnant women and the disabled) }\end{array}$ & 5 & $2.6 \%$ & 171 & $88.1 \%$ & 18 & $9.3 \%$ \\
\hline
\end{tabular}

Table (9) reveals Frequency distribution of nurses' readiness regarding accessing critical. More than half 59.3\% of the nurses had moderate level of readiness regarding during an event where to quickly access up-to-date resources about specific (chemical, biological, radiological, nuclear, and explosive) agents, whereas only $2.6 \%$ nurses had low level of readiness related to it. Similarly, more than half $(58.2 \%)$ of the nurses had moderate level of readiness and less than one-third $(22.7 \%)$ nurses had high level of readiness in terms of how to determine the appropriate agency to which reportable disease are to be directed. Moreover, more than half $(54.1 \%)$ had moderate level of readiness whereas less than one-third (24.2\%) had high level of readiness for the process for gaining access to the Strategic National Stockpile (SNS).

Table (9): Frequency distribution of nurses' readiness regarding accessing critical $(n=194)$

\begin{tabular}{|l|l|l|l|l|l|l|}
\hline \multirow{2}{*}{ Items } & \multicolumn{2}{l}{$\begin{array}{l}\text { Low } \\
(\mathbf{1})\end{array}$} & \multicolumn{2}{l|}{$\begin{array}{l}\text { Moderate } \\
(\mathbf{2})\end{array}$} & \multicolumn{2}{l|}{$\begin{array}{l}\text { High } \\
\mathbf{( 3 )}\end{array}$} \\
\cline { 2 - 7 } & $\mathbf{N}$ & $\mathbf{\%}$ & $\mathbf{N}$ & $\mathbf{\%}$ & $\mathbf{N}$ & $\mathbf{\%}$ \\
\hline $\begin{array}{l}\text { During an event, where to quickly access up-to- } \\
\text { date resources about specific (chemical, biological, } \\
\text { radiological, nuclear, and explosive) agents }\end{array}$ & 35 & $18.0 \%$ & 115 & $59.3 \%$ & 44 & $22.7 \%$ \\
\hline $\begin{array}{l}\text { Determine the appropriate agency to which } \\
\text { reportable disease are to be directed }\end{array}$ & 37 & $19.1 \%$ & 113 & $58.2 \%$ & 44 & $22.7 \%$ \\
\hline $\begin{array}{l}\text { The process for gaining access to the Strategic } \\
\text { National Stockpile (SNS) }\end{array}$ & 42 & $21.6 \%$ & 105 & $54.1 \%$ & 47 & $24.2 \%$ \\
\hline
\end{tabular}

Table (10) shows that when nurses were asked to assess their own overall preparedness with response activities/preparedness in the case of a large-scale emergency event, according to them more than half $(54.6 \%)$ of the nurses were having moderate level of readiness while $12.9 \%$ reported low level of readiness. Similarly, more than half $(51.5 \%)$ of the nurses reported moderate level of readiness if they had to respond to a major disaster in their hospital/community today, and $9.8 \%$ of the nurses reported that they had low level of readiness related to it. Table (10) shows Frequency distribution point of view nurses 'own readiness $(n=194)$

\begin{tabular}{|l|l|l|l|l|l|l|}
\hline \multirow{2}{*}{ Items } & \multicolumn{2}{l|}{$\begin{array}{l}\text { Low } \\
\text { (1) }\end{array}$} & $\mathbf{N}$ & $\mathbf{N}$ & $\mathbf{2}$ & \multicolumn{2}{l|}{$\begin{array}{l}\text { Moderate } \\
\text { (2) }\end{array}$} \\
\cline { 2 - 7 } & $\mathbf{N}$ & $\mathbf{\%}$ & $\mathbf{N}$ & $\%$ \\
\hline $\begin{array}{l}\text { Please provide an assessment of your overall } \\
\text { readiness with response activities/preparedness } \\
\text { in the case of a large-scale emergency event }\end{array}$ & 25 & $12.9 \%$ & 106 & $54.6 \%$ & 63 & $32.5 \%$ \\
\hline $\begin{array}{l}\text { If you had to respond to a major disaster in } \\
\text { your hospital/community today, how prepared } \\
\text { do you feel to effectively respond? }\end{array}$ & 19 & $9.8 \%$ & 100 & $51.5 \%$ & 75 & $38.7 \%$ \\
\hline
\end{tabular}

Figure.1 reveals the overall nurse's readiness for disaster preparedness. Regarding total level of readiness, $9.3 \%$ of the nurses had low level of readiness, and near a half, (49\%) of the nurses had moderate level of readiness. Concerning preparedness' terms, activities more than half of the nurses $(52.6 \%)$ had moderate level of readiness, and $10.8 \%$ had low level of readiness. Whereas, $9.3 \%$ of the nurses had low level of readiness regarding ethical issues in triage and less than half of the nurses $(39.7 \%)$ had moderate level of readiness related to it. Moreover, $10.3 \%$ of the nurses had low readiness whereas less than a half of the nurses $(47.9 \%)$ had moderate level of readiness regarding epidemiology and surveillance. In addition, more over $10.3 \%$ of the nurses had low readiness and less than a half of them $(43.3 \%)$ had moderate level of readiness regarding decontamination during disaster event. Moreover, $11.3 \%$ of the nurses had low readiness whereas; more than half of the nurses $(52.1 \%)$ had moderate level of readiness regarding communication/ connectivity. In respect of readiness with Psychological issues, $10.8 \%$ of the nurses had low whereas about half $49.5 \%$ of the nurses had moderate level of readiness. Likewise, only $2.1 \%$ of the nurses had low level of readiness and majority of them $(71.1 \%)$ had moderate level of readiness regarding special populations. In terms accessing critical, less than one-third (19.1\%) of the nurses had 
low level of readiness and half (51\%) of the nurses had moderate level of readiness. Lastly, nurses' awareness and readiness showed that $9.3 \%$ nurses had low level of readiness and about half of the nurses $(51 \%)$ had moderate level of readiness.

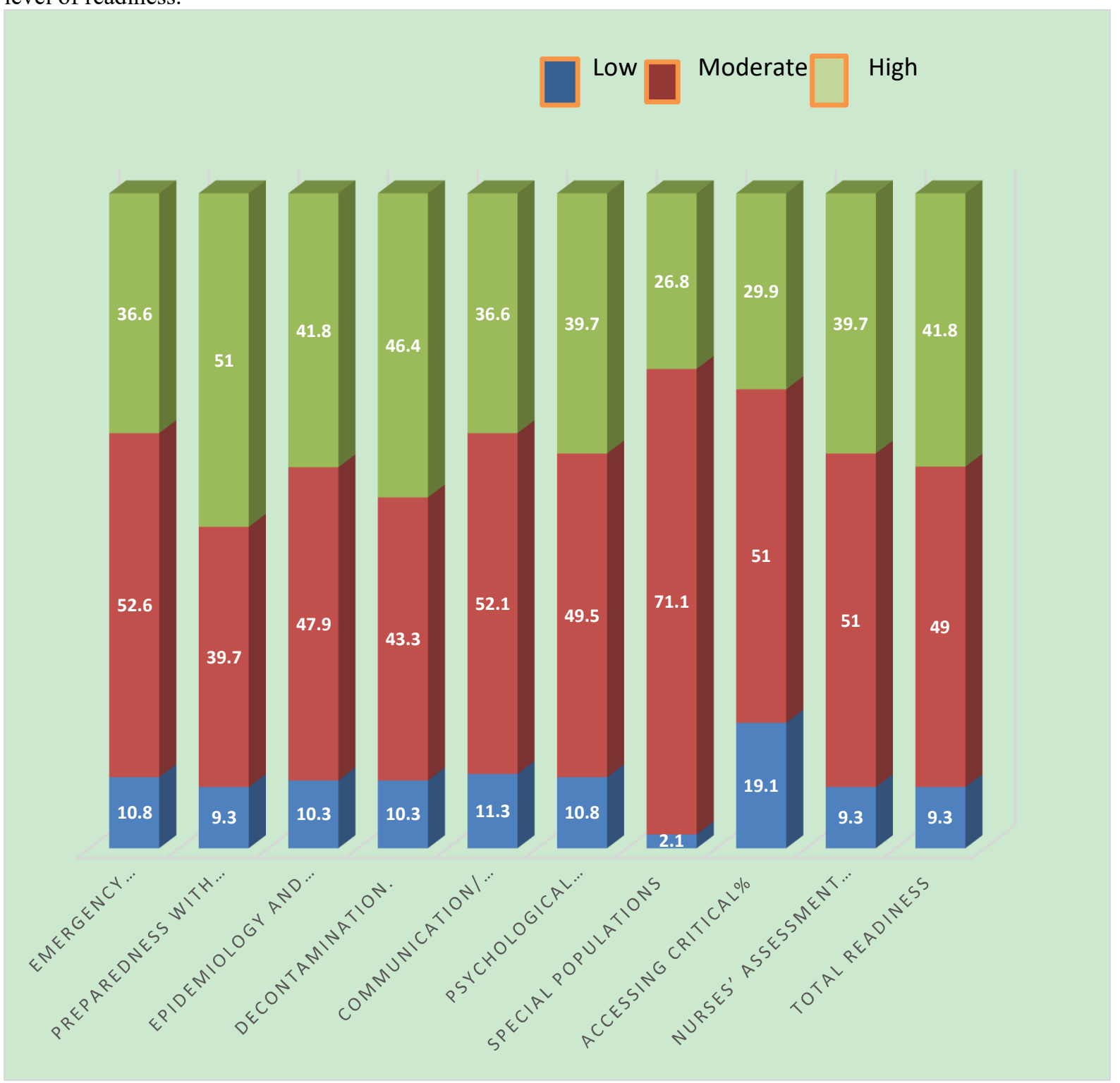

Figure1. Over all Nurses readiness regarding disaster preparedness

\subsection{Relationship of demographic and work related characteristic with Nurses' level of Readiness for their Disaster Preparedness}

Table 2 shows the relationship of demographic and work-related characteristic with nurses' level of readiness for their disaster preparedness. There were no significant relationships between age, gender, education level of nurses, and years of experience, attended of previous drill workshop with the nurses' readiness for disaster preparedness ( $p$ values $0.196,0.418,0.805,0.133,0.216$ ) respectively. While there is a significant relationship between nurses' readiness for disaster preparedness with the specialty practice area of nurses. Nurses' readiness for disaster preparedness varies with working in different specialty areas such as medical unit, surgical unit, critical care unit and emergency care unit $p$ value (0.000). In addition, for current professional role the $p$ value $(0.004)$ depicted that there is a significant relationship between nurses' readiness for disaster preparedness level with their current professional role. Likewise, for nurses actively participated in an actual major disaster event the p value $(0.001)$ which shows that there is a significant relationship between nurses' readiness for disaster preparedness and their active participation in disaster. 
Table 11. Relationship of demographic and work related characteristic with Nurses' Readiness for Disaster Preparedness

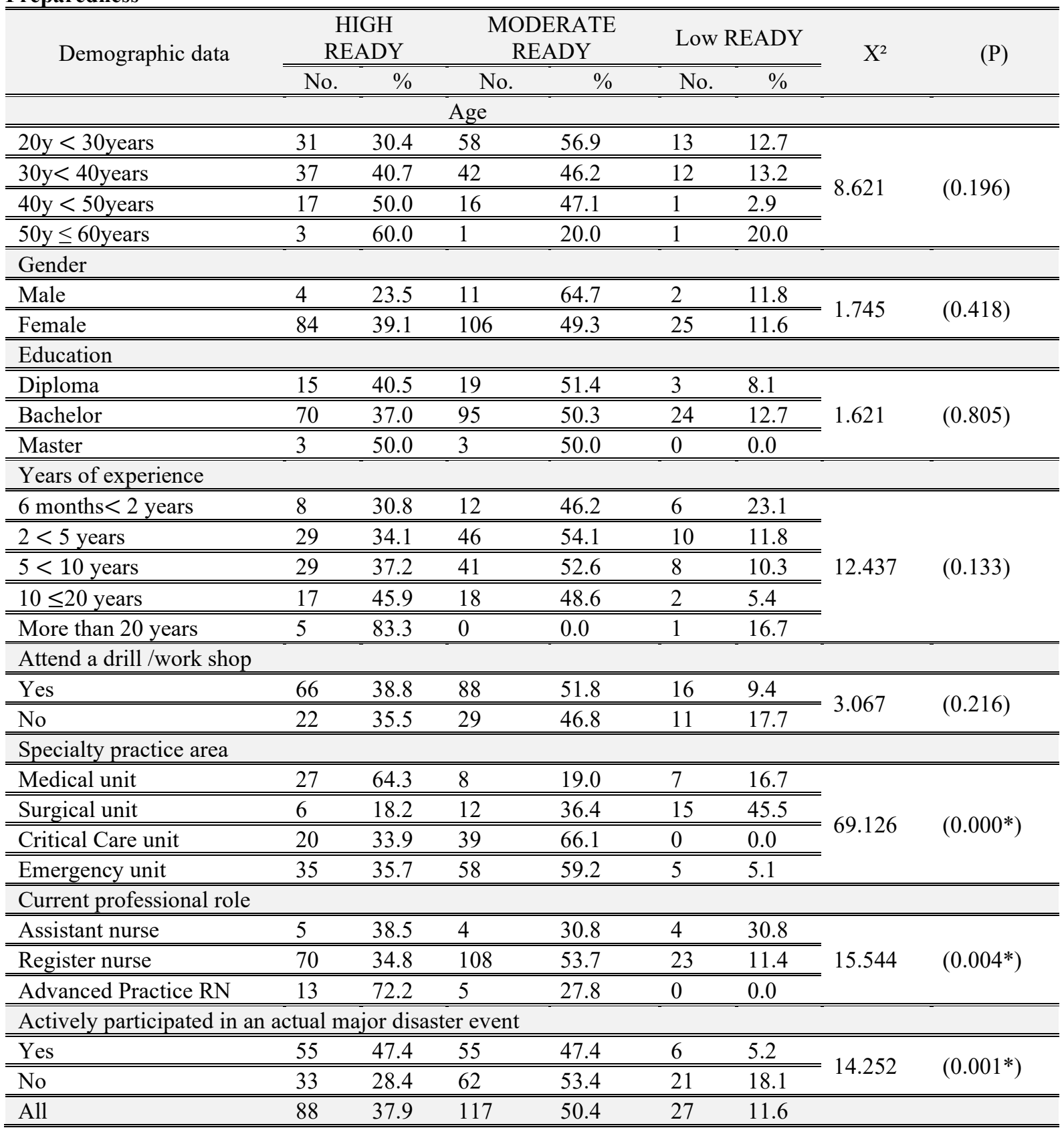

\subsection{DISCUSSION}

Globally there are increasingly frequent disasters are posing threats to human health and life. So, World Health Organization (WHO) emphasized all countries to have a disaster plans at all levels in order to be prepared for any kind of disasters that may arise at any time. Researchers believe that formulating and development a comprehensive disaster plan and good training of individuals participating in the disaster especially the nurses help to proper management when disaster occurs. Nurses play a key role in the health system and must be prepared for appropriate response in disasters. Furthermore, previous experiences and trainings of nurses affect their preparedness, increase their awareness, self-confidence and skills in disaster response and decrease their vulnerability to unpredictable events. Studies show that most nurses are not ready to face mass casualties, and their preparedness, education and skills are not adequate for an appropriate response. The aim of this study was to evaluate the nurses' readiness regarding disaster preparedness. At the beginning the demographic data will be discussed, then the results of the nurse's readiness regarding preparedness, and finally the relation between the demographic data and the nurses' readiness regarding disaster preparedness will discuss.

In overall view of the present study findings; nearly half of the nurses were aged from $20<30$ years old, 
female nurses were the highest in this study. This might be related to the high ratio of female nurses comparing to male nurses due to the concept of nursing as female profession. These results are consistent with Alshehri, (2017) and Nofal, et al., (2018) in Saudi Arabia and other study conducted in India by Khan, Kausar, and Ghani, (2017) who reported that majority of the respondents were female, while it inconsistent with Alzahrani, and Kyratsis, (2014) who reported that more than half of nurses' participants were males. Ibrahim, (2014) and Nofal, (2018) reported majority of the study participants were aged below 30-year-old, while study of Alzahrani, and Kyratsis, (2014) revealed majority of nurses were of age between 20-40 years old.

The study revealed that nearly one third of nurses had period of experience ranged from $2<5$ years, this result consistent with Ibrahim (2014), Alzahrani, and Kyratsis, (2014) and Khan, Kausar, and Ghani, (2017) who reported that the period of experience for one third of participants ranged between 2 to 5 years.

Regarding education, majority of the nurses were holding bachelor degree in nursing and working as register nurse. This might due to hospital preferred nurse with high education and good experience to provide good quality of care for all patients. This result is similar to Alshehri, (2017) who reported $70 \%$ of the respondents were registered nurse. While this result is inconsistent with study of Khan, Kausar, and Ghani, (2017) who reported that more than half of participants had diploma in General Nursing.

The present study revealed that more than two third of nurses attended drill or workshop training related to disaster management. Education and training on disaster preparedness varied significantly by the nurses in this study participants held. Involvement in disaster exercises needs to become more standardized and inclusive for all nursing working in the Emergency Department. Alzahrani, \& Kyratsis, (2017) reported that The need for disaster preparedness training is well documented in the literature. Ministry of Health in Saudi Arabian has undertaken extensive education and training programs for nurses especially who work in Emergency Departments and this was somehow reflected in the participants' responses This result is similar to the study of Nofal, et al., (2018) who reported that $(81 \%)$ participants attended disaster drill at their hospital. Moreover, Alshehri, (2017) mentioned that two-thirds $(63.2 \%)$ of respondents had undertaken disaster training provided at their hospital. A previous study by Ogedegbe et al, (2012) also highlighted the importance of disaster preparedness training among healthcare providers. Another study by Corrigan et al, (2012) assessing disaster preparedness in an Australian urban trauma center reported that $59.3 \%$ participants were previously trained to handle disaster, $(37.9 \%)$ had attended drill for disaster simulation whereas, $(12.9 \%)$ had actually handled a disaster.

Present results showed that more than half of nures had never actively participated in an actual major disaster event and nearly three quarter of nurses had never worked in a post-disaster shelter. This result is consistent with Alshehri, (2017) who reported that less than half of nurses involved in an actual disaster like mass casualties and natural disaster.

Nurses' readiness regarding disaster preparedness terms and activities, result showed that more than half of nurses had moderate readiness for sign and symptoms of anthrax inhalation, match of antidote and prophylactic medications to specific biological/chemical agents. more than half in knowing possible adverse reactions to smallpox vaccination, basic first aid in a large-scale emergency event including oxygen administration and ventilation, basic first aid in large emergency event and evaluation of their own actions during a large-scale emergency event. This result is contradicted with result of Ibrahim, (2014) who mentioned that only one third of nurses are moderate readiness regarding emergency preparedness terms and activities.

Moreover, also it is contradicted with study of Nofal, (2018) who reported that majority of the participants have high readiness regarding emergency preparedness terms and activities. Tzeng, et al., (2016) reported that nurses demonstrated poor readiness in response to disaster situations. Öztekin et al. (2016) reported that nurses felt they were not able to respond in a variety of disaster situations, aware of their workplace emergency disaster plan, but did not think they could execute them, and were not aware of the level of preparedness of the healthcare systems in their communities.

Regarding ethical issue in Triage, the present study illustrated that nearly two third of the nurses had moderate readiness related to performance of rapid physical assessment of victim of a large-scale emergency event, performance of rapid physical assessment of victim of a large-scale emergency event, performance of rapid mental health assessment of a victim of a large-scale emergency event, while around half of participants have moderate readiness related to assist with triage in a large-scale emergency event, proper handling of the dead during a largescale emergency event such as ethical, legal, cultural, and safety. This result is consistent with result of Ibrahim, (2014) who mentioned that the nurses have moderate readiness with ethical issues in triage. While it is contradicted with result of Sultan, Mary, and Al Grad, (2017) who reported that less than half of participants were ready with ethical issues in triage.

Regarding epidemiology and surveillance, the result revealed that more than half of the nurses had moderate readiness regarding appropriate personal protective equipment when caring for patient exposed to a biological, chemical, or radiological agent, Time to report an unusual set of symptoms to an epidemiologist, diseases that are immediately reported to state health departments and ability to identify the exacerbation of an underlying disease due to exposure to a chemical or biological agent, or to radiation. So, this result is consistent with result of Ibrahim, 
(2014) who reported that nurses have moderate readiness for epidemiology and surveillance. Another study conducted by Alzahrani, and Kyratsis, (2017) mentioned that the nurses are expected to perform a wide range of clinical activities include prevention, surveillance, general assessment and caring of patient, triage, resuscitation, leadership and psychological care. They also seem to be geared towards the clinical tasks of acute care provision rather than the more proactive clinical activities of surveillance and prevention.

Regarding decontamination, the present result revealed that more than half of the nurses had moderate readiness for respect of selection of the appropriate personal protective equipment (PPE) when caring for patients exposed to a biological, chemical or radiological agent, decontamination procedures stated in facility's emergency operations plan and impact on environment from a large-scale emergency event. This is consistent with results of Al Khalaileh, and Bond, (2013) and Ibrahim, (2014) who reported that most of nurses are moderate readiness regarding disaster preparedness depicts the frequency distribution of nurses' readiness regarding decontamination, while this result contradict with Ibrahim, (2014) who mentioned that nearly one third of nurses are moderate readiness regarding decontamination.

The present result revealed nurses' readiness regarding communication and connectivity. It illustrated that more than half of nurses had moderate level of readiness regarding appropriate debriefing activities following large scale emergency event, use all type of communication devices, chain of custody during a large-scale emergency event, and procedure for communicating critical patient information to those transporting patient.

This result is similar to the result of Ibrahim (2014) who mentioned that more than half of nurses are moderate readiness regarding communication and connectivity, while this result contradicted with results of Nofal, (2018) and Sultan, Mary, and Al Grad, (2017) who reported that the majority of the participants have high readiness regarding communication and connectivity.

Regarding psychological issues, the result revealed that more than half of the nurses had moderate readiness in provide health counseling and education to patient regarding the long-term impact of Chemical, Biological, Radiological, Nuclear and Explosive (CBRNE) agents, signs of post-traumatic stress in patients seen for routine health care following an event, and the evaluation of a teenager to detect post-traumatic mental health problems. This result is consistent with result of Sultan, Mary, and Al Grad, (2017) who reported that more than half of nurses have moderate readiness regarding psychological issues, while contradicted with result of Ibrahim, (2014) who mentioned that one third of the nurses have moderate readiness regarding psychological issues.

Furthermore, the present result revealed that more than half of the nurses had moderate readiness regarding special populations; related to procedures for providing care to children or youth during a large-scale emergency event in cases where prior consent from parent or legal guardian is not possible, while majority of nurses have the appropriate care of sensitive and vulnerable patient groups during a large-scale emergency as aged, and pregnant women and the disabled. This result is consistent with results of Sultan, Mary, and Al Grad, (2017) and Ibrahim, (2014) who reported that majority of nurses have moderate readiness regarding special population.

Also, the result revealed that more than half of the nurses had moderate readiness regarding accessing critical; during an event where to quickly access up-to-date resources about specific (chemical, biological, radiological, nuclear, and explosive) agents, how to determine the appropriate agency to which reportable disease are to be directed, the process for gaining access to the Strategic National Stockpile (SNS). This result is consistent with result of Sultan, Mary, and Al Grad, (2017) who reported that more than half of nurses have moderate readiness regarding accessing critical issues.

Regarding to nurses' preparedness with response activities/preparedness in the case of a large-scale emergency event, when nurses were asking to assess their own overall readiness from their point of view, the result revealed that more than half of the nurses were having moderate readiness and respond to a major disaster in their hospital/community.also this result congrant with Al Thobaity, et al. (2015) and Ibrahim, (2014) reported that most of nurses perceived themselves to be moderately prepared for disaster events. Another recent study by Shalhoub, et al, (2017) identifying disaster preparedness in hospitals covering both internal and external disasters reported high awareness and more than two third participants were confident in terms of disaster handling and consistent with the study of Nilsson, et al. (2016) who reported that nurses were moderately prepared to manage emergencies and disaster events.

This result contradicted with result of Tzeng, et al., (2016) who reported that nurses demonstrated poor readiness for disaster responses. Öztekin, et al. (2016) reported low mean scores for disaster readiness which indicated a low level of self-reported readiness for disaster response. While the findings of a descriptive survey approach conducted by Khan, Kausar, \& Ghani (2017) demonstrated that $48 \%$ of nurses had inadequate disaster preparedness knowledge at two tertiary care hospitals in Lahore. Labrague, et al. (2016) found that approximately $80 \%$ of nurses recognized they were not sufficiently prepared and were not confident in responding effectively to any disasters. Another study was conducted by Baack, \& Alfred, (2013) found that most nurses were not confident in their abilities to respond to major disaster events. While another study conducted by Alzahrani, \& Kyratsis, (2017) on Emergency nurse covering both internal and external disaster preparedness during mass gatherings of hospitals in Makkah, Saudi Arabia reported high awareness and more than two third participants were confident 
in terms of disaster handling.

Finally regarding total overall nurse's readiness, nearly half of nurses had moderate level of readiness regarding disaster preparedness, this result is consistent with the result of a study conducted in Saudi Arabia at Ministry of Health Hospitals by Sultan, Mary, \& Al Grad, (2017) who found that $55 \%$ of the emergency nurses had moderate readiness on disaster preparedness.

Regarding relation between demographic and work related characteristics with nurse's readiness, the result revealed that there were no statistically significant relationships between age, gender, education level of nurses, and years of experience, attended of previous drill workshop with the nurses' readiness for disaster preparedness. Contrary to this, regarding specialty practice area, there is a significant relationship between nurses' readiness for disaster preparedness with the specialty practice area of nurses.

Nurses' readiness for disaster preparedness varies with working in different specialty areas such as medical unit, surgical unit, critical care unit and emergency care unit. Whereas, for current professional role depicted that there is a significant relationship between nurses' readiness for disaster preparedness with their current professional role. This result is consistent with result of Sultan, Mary, \& Al Grad, (2017) who reported that nurses working in Emergency Department have high awareness and disaster response; nurses have limited knowledge and awareness of the wider emergency and disaster preparedness.

According to study of Khan, Kausar, \& Ghani (2017), found statistically significant differences in the knowledge scores in Four Year BScN graduates scored significantly better than diploma and Post-RN BScN graduates.

\subsection{CONCLUSION}

Based on the results concerning total readiness this study concluded that nearly half of the nurses had moderate readiness regarding disaster preparedness'. Moreover, more than half of nurses had moderate readiness regarding emergency preparedness terms and activities, communication and connectivity, assessing critical and nurse's assessment readiness. While less than half of nurses had moderate readiness regarding ethical issues in triage, epidemiology and surveillance, decontamination and psychological issue. In addition, there was no significant relationship between nurses' readiness for disaster preparedness with age, gender, education level of nurses, and years of experience, attended previous drill workshop, while there was significant relationship with the specialty practice area of nurses. Nurses' readiness for disaster preparedness varies with working in different specialty areas such as Medical Unit, Surgical Unit, Critical Care Unit and Emergency Care Unit. Whereas, for current professional role depicted that there was a significant relationship between nurses' readiness for disaster preparedness with their current professional role. Furthermore, Nurses show different readiness for disaster preparedness when they are working as assistant nurse, register nurse and advance practice RN. Likewise, there was a significant relationship between nurses' readiness for disaster preparedness and their active participation in disaster event. 6.0

\section{RECOMMENDATIONS}

The finding from current work recommended several actions as follow:

1. Hospital and nurse's managers should provide all the learning resources needed to enhance nurse's readiness regarding disaster preparedness.

2. The result of current study should be share with stakeholders at Makkah to establish educational program for the nurses in the area.

3. Nursing education department should provide in-service education and training about disaster preparedness that base on recent evidence to all new staff as part of their orientation program as well as refresh course to both senior and juniors nursing staff.

\section{References}

Achora, S. \& Kamanyire, J.K. (2016). Disaster Preparedness: Need for inclusion in undergraduate nursing education. Sultan Qaboos University Medical Journal. Vol.16 Issue (1). pp,e15-9.

Abosuliman, S. Kumar, A. \& Alam, F. (2013). Disaster preparedness and management in Saudi Arabia: An empirical investigation. International Journal of Social, Human Science and Engineering. Vol.7Issue(12). PP, 295-299.

Alamri, Y.A. (2010). Emergency Management in Saudi Arabia: Past, Present and Future. Un. Of Christchurch report, New Zealand.

Alharbi, T. (2013). The Cause of Flood Disaster in Saudi Arabia, in Proceedings of the First Saudi International Conference on Crisi and Disaster Management, Riyadh, KSA.

Al-Khalaileh, M. Bond, E. \& Alasad, J. (2012). Jordanian nurses' perceptions of their preparedness for disaster management. International Emergency Nursing. Vol.20. pp,14-23.

Alshehri, B. (2017). Emergency nurses' preparedness for disaster in the Kingdom of Saudi Arabia. Journal of 
Nursing Education and Practice. Vol.7 Issue (3). pp, 101-114.

Al Thobaity, A. Plummer, V. Innes, K. \& Copnell, B. (2015). Perceptions of knowledge of disaster management among military and civilian nurses in Saudi Arabia. Australasian Emergency Nursing Journal. Vol.18 Issue (3). pp, 156-164.

Alzahrani, F. \& Kyratsis, Y. (2017). Emergency nurse disaster preparedness during mass gatherings: A crosssectional survey of emergency nurses' perceptions in hospitals in Mecca, Saudi Arabia. BMJ Journal. Vol. 7 Issue (4). pp,12-15.

Baack, S. \& Alfred, D. (2013). Nurses' preparedness and perceived competence in managing disasters. Journal of Nursing Scholar. Vol.45 Issue (3). pp, 281-287.

Bin Shalhoub, A.A. Khan, A.A. \& Alaska, Y.A. (2017). Evaluation of disaster preparedness for mass casualty incidents in private hospitals in Central Saudi Arabia, Saudi Medical Journal. Vol.38 Issue (3). pp,302-306.

Corrigan, E. \& Samrasinghe, I. (2012). Disaster preparedness in an Australian urban trauma center: staff knowledge and perceptions. Prehospital and Disaster Medicine. Vol.27 Issue (05). pp, 432-438.

Diab, G.M. \&Mabrouk, S.M. (2015). The effect of guidance booklet on knowledge and attitudes of nurses regarding disaster preparedness at hospitals. Journal of Nursing Education and Practice. Vol.5 Issue (9). pp17-31.

Evans, C.A. \& Baumberger-Henry, M. (2014). Readiness: how prepared are you?. Journal of Emergency Nursing. Vol.40 Issue (5). pp, 448-52.

Guha-Sapir, D. Hoyois, P. and Below, R. (2017). Annual Disaster Statistical Review: Numbers and Trends 2013 (No. UCL-Université Catholique de Louvain).

Ibrahim, F.A.A. (2014). Nurses Knowledge, Attitudes, Practices and Familiarity Regarding Disaster and Emergency Preparedness - Saudi Arabia, American Journal of Nursing Science. Vol. 3 Issue(2). pp,18-25.

Khan, S. Kausar, S. \& Ghani, M. (2017). Knowledge of Disaster Preparedness among Nurses at Two Tertiary Care Hospitals in Lahore. Biomedica. Vol. 33 Issue (1). pp, 29-32.

Labrague, L. Yboa, B. Petitte, D. Lobrino, L. \& Brennan, M. (2016). Disaster :Preparedness in Philippine Nurses, Journal of Nursing Scholarship, Vol.48 Issue(1). pp, 98-105.

Lowe, L.D. \& Hummel, F.I. (2014). Disaster readiness for nurses in the workplace: preparing for the Zombie Apocalypse. Workplace Health \& Safety. Vol. 62 Issue (5). pp, 207-13.

Magnaye, B. Lindsay, Muñoz, M. A.F. Muñoz, G.R. and Muro, GJ. (2011). The role, preparedness and management of nurses during disasters. E-Int. Sci. Res. Journal. Vol.3. pp,269-294.

Nilsson, J. (2016). Disaster nursing: Self-reported competence of nursing students and registered nurses, with focus on their readiness to manage violence, serious events and disasters, Nursing Education Practice. Vol.17. pp, 102-108.

Nofal, A. Alfayyad, I. Khan, A. Al Aseri, Z. and A. Abu-Shaheen, Knowledge, attitudes, and practices of emergency department staff towards disaster and emergency preparedness at tertiary health care hospital in central Saudi Arabia, Saudi Medical Journal. Vol. 39 Issue (11). pp,1123-1129.

Pourvakhshoori, N. Norouzi, K. Ahmadi, F. Hosseini, M.A. \& Khankeh, H.R. (2014). Nursing in Disasters: A Review of Existing Models. Health in Emergencies and Disasters. pp161-165.

Ogedegbe, C. Nyirenda, T. Delmoro, G. Yamin, E. \& Feldman, J. (2012). Health care workers and disaster preparedness: barriers to and facilitators of willingness to respond. International Journal of Emergency Medicine, Vol. 5. pp, 29.

Öztekin, S.D. Larson, E.E. Akahoshi, M. \& Öztekin, İ. (2016). Japanese nurses’ perception of their preparedness for disasters: quantitative survey research on one prefecture in Japan. Japan Journal of Nursing Science. Vol.13 Issue (3). pp, 391-401.

Sultan, M. Mary, P.E. \& Al Grad, H.S. (2017). Emergency Nurses Readiness for Disaster Response-An Explorative Study, American Research Journal of Nursing. Vol.4 Issue (1). pp, 1-10.

Tzeng, W.C. et al., (2016).Readiness of hospital nurses for disaster responses in Taiwan: a cross-sectional study, Nurse Education Today. Vol.47. pp, 37-42.

Turale, S. (2014). Disaster training for nurses: a moral and humanitarian imperative, International nursing review. Vol.61 Issue (1). pp,3-3.

Usher, K. et al. (2015). Cross-sectional survey of the disaster preparedness of nurses across the Asia-Pacific region. Nursing \& Health Sciences. Vol.17 Issue (4). pp, 434-443. 